\title{
La lengua como elemento modelador del mundo que nos rodea: experiencias de Aprendizaje Servicio en la asignatura de Lengua Española y su Didáctica
}

\section{Language as a shaping tool of the world around us: Service Learning experiences in the subject Teaching Spanish Language}

CONCEPCIÓN TORRES BEGINES

ORCID: https://orcid.org/0000-0002-9868-3924

Departamento de Didáctica de la Lengua

y la Literatura y Filologías Integradas

Facultad de CC de la Educación

Universidad de Sevilla

ctorres3@us.es

Fecha de recepción: 20-11-2019.

Fecha de aceptación: 25-11-2019.

DOI: http://dx.doi.org/10.12795/9788447221912.120

Pp.: 2652-2680 


\section{Resumen:}

Este trabajo se centra en la inclusión y puesta en valor de contenidos actitudinales como los movimientos migratorios, el racismo, la igualdad de género, el cambio climático y la educación como motor de cambio social en la asignatura de Lengua Española y su Didáctica. Estos temas han sido trabajados de manera transversal a los contenidos conceptuales de los bloques relativos a los niveles nivel léxico-semántico, morfológico y sintáctico, buscando así la adquisición de las competencias básicas y el aprendizaje significativo de los futuros maestros de Educación Primaria. Para ello partimos del Aprendizaje Servicio con el diseño de proyectos solidarios por parte del alumnado aplicando los contenidos adquiridos, de los que presentan los logros de la primera fase, centrada en la exploración del entorno y la detección de necesidades. Entre los resultados obtenidos destacamos la adquisición de los contenidos conceptuales de manera significativa, apreciando una gran acogida por parte del alumnado respecto a la manera de presentarlos, además de un desarrollo del pensamiento crítico y de la conciencia social.

Palabras clave: Aprendizaje Servicio, docencia universitaria, experimentación docente universitaria, Grado en Educación Primaria, Lengua Española y su Didáctica.

\section{Abstract:}

This work focus on the development of attitudinal contents as migration, racism, gender equality, climate change and education as tools for social change in Teaching Spanish Language. These topics have been treated among lexical-semantic, morphological and syntactical levels, reaching the acquisition of basic skills and deep learning by future Primary School teachers. With this aim, we have applied the Service Learning methodology in the design of solidary projects by part of the class. Along this article, we present the results obtained during the first phase, centered on the exploration of the world and the detection of social needs. Among these we highlight the deep learning of the main concepts, finding a warm welcome by the students on the way they have been presented, in addition to the development of the critical thinking and social competence.

Keywords: Service Learning, improvement of the university teaching, Primary Education Degree, Teaching of the Spanish Language, university teaching.

Jornadas de Formación e Innovación Docente del Profesorado | № 2 (2019)

Esta obra se distribuye con la licencia Creative Commons

Reconocimiento-NoComercial-SinObraDerivada $\quad 4.0$ Internacional (CC BY-NC-ND 4.0.) 


\section{Descripción del contexto y relación con acciones anteriores}

El CIMA se ha aplicado en la asignatura de Lengua Española y su Didáctica del tercer curso del Grado de Educación Primaria de la Facultad de Ciencias de la Educación, en la que ya se implementaron varios cambios el curso pasado. Partimos, por tanto, de la remodelación de uno de los bloques (nivel léxico-semántico), llevada a cabo en el curso 2018/2019, para seguir incluyendo mejoras, incluyendo además el nivel morfológico y el sintáctico, que quedan enlazados con el primero.

Algunos de los cambios introducidos fueron la reformulación de la asignatura, convirtiéndola en una asignatura eminentemente práctica, lo que sorprendió, por ser considerada popularmente como muy teórica, y la introducción del Aprendizaje Servicio, que dota a los contenidos de una aplicación de carácter social y solidario, con la formulación y aplicación de proyectos. En este curso, y de nuevo dentro de un proyecto de la Oficina de Cooperación al Desarrollo, colaboramos con cuatro ONGs locales: Tiritas Creativas, Claver, Madre Coraje y Solidaridad Don Bosco, quienes han acogido a los alumnos dentro de sus proyectos y han tenido la oportunidad de dinamizar dos de las sesiones, contribuyendo a la formación integral del alumnado.

\section{Mapa de contenidos y problemas}

Presentamos en primer lugar un mapa de contenidos en el que se puede apreciar la organización de la asignatura, entendida como una gradación en los diferentes niveles de estudio, aspecto que se ha respetado, dándole un mayor valor a la relación que se establece entre ellos, recogiendo en cada nuevo bloque los contenidos del anterior.

Jornadas de Formación e Innovación Docente del Profesorado | № 2 (2019)

Esta obra se distribuye con la licencia Creative Commons 


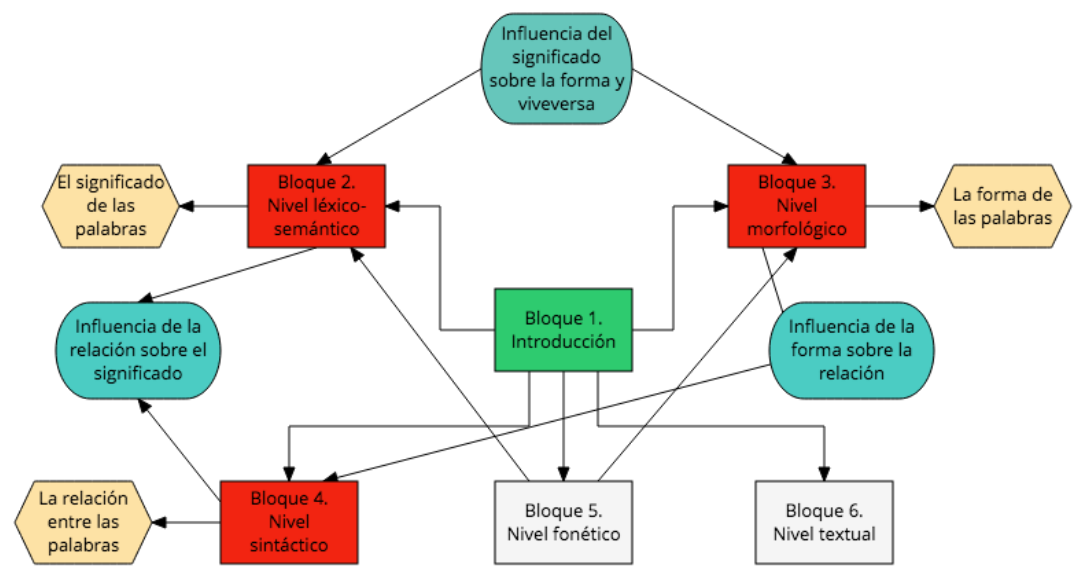

Figura 1. Mapa de organización de la asignatura

Para facilitar su lectura se han marcado en rojo los tres bloques del ciclo de mejora y en azul la relación que se establece entre ellos y que va a funcionar como transición, de manera que los contenidos se siguen trabajando de manera transversal. En los laterales (amarillo), aparece el tema nuclear. El Bloque 1 está marcado en verde porque, al ser un tema que funciona como marco de toda la asignatura, varía conforme se van aplicando nuevos ciclos de mejora. Por último, se han marcado las posibles futuras relaciones.

Presentamos a continuación los mapas de contenido de los tres bloques del CIMA, con un total de 30 horas. Para facilitar la localización de los contenidos y la lectura del mapa, hemos establecido tres categorías: 1) contenidos conceptuales (SABER); 2) contenidos procedimentales (SABER HACER); 3) contenidos actitudinales (SABER SER).

Jornadas de Formación e Innovación Docente del Profesorado | № 2 (2019)

Esta obra se distribuye con la licencia Creative Commons 
La lengua como elemento modelador del mundo que nos rodea: experiencias de Aprendizaje Servicio en la asignatura de Lengua Española y su Didáctica CONCEPCIÓN TORRES BEGINES

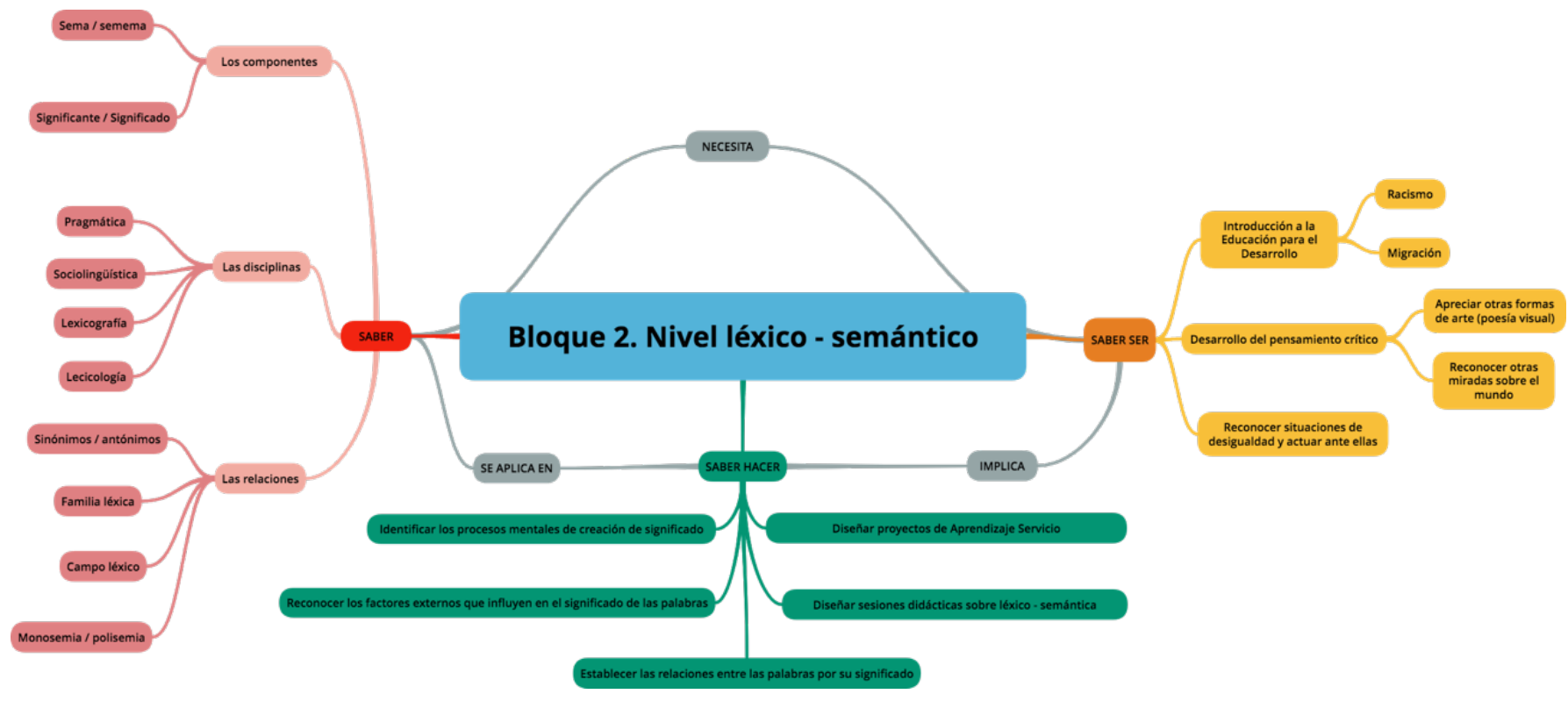

Figura 2. Mapa de contenidos Bloque 2. Nivel léxico - semántico

Jornadas de Formación e Innovación Docente del Profesorado | № 2 (2019)

(C) (i) $($ Esta obra se distribuye con la licencia Creative Commons Internacional (CC BY-NC-ND 4.0.) 
La lengua como elemento modelador del mundo que nos rodea: experiencias de Aprendizaje Servicio en la asignatura de Lengua Española y su Didáctica CONCEPCIÓN TORRES BEGINES

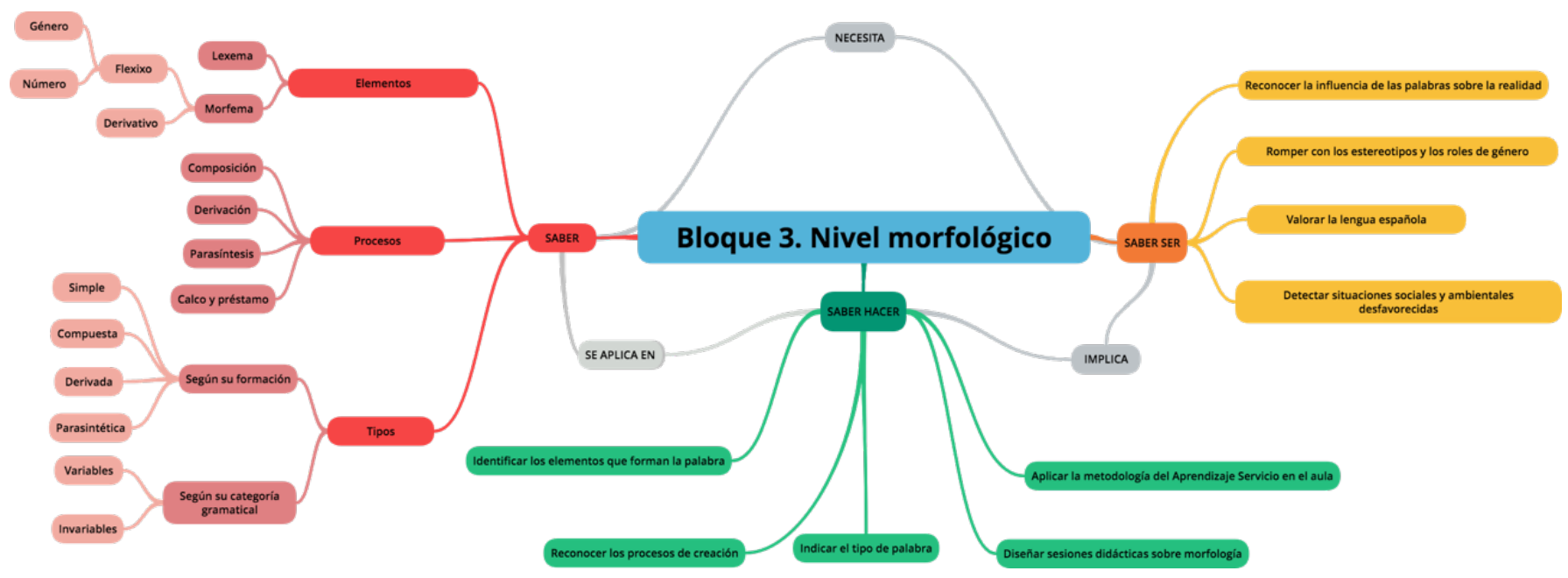

Figura 3. Mapa de contenidos Bloque 3. Nivel morfológico

Jornadas de Formación e Innovación Docente del Profesorado | № 2 (2019) 


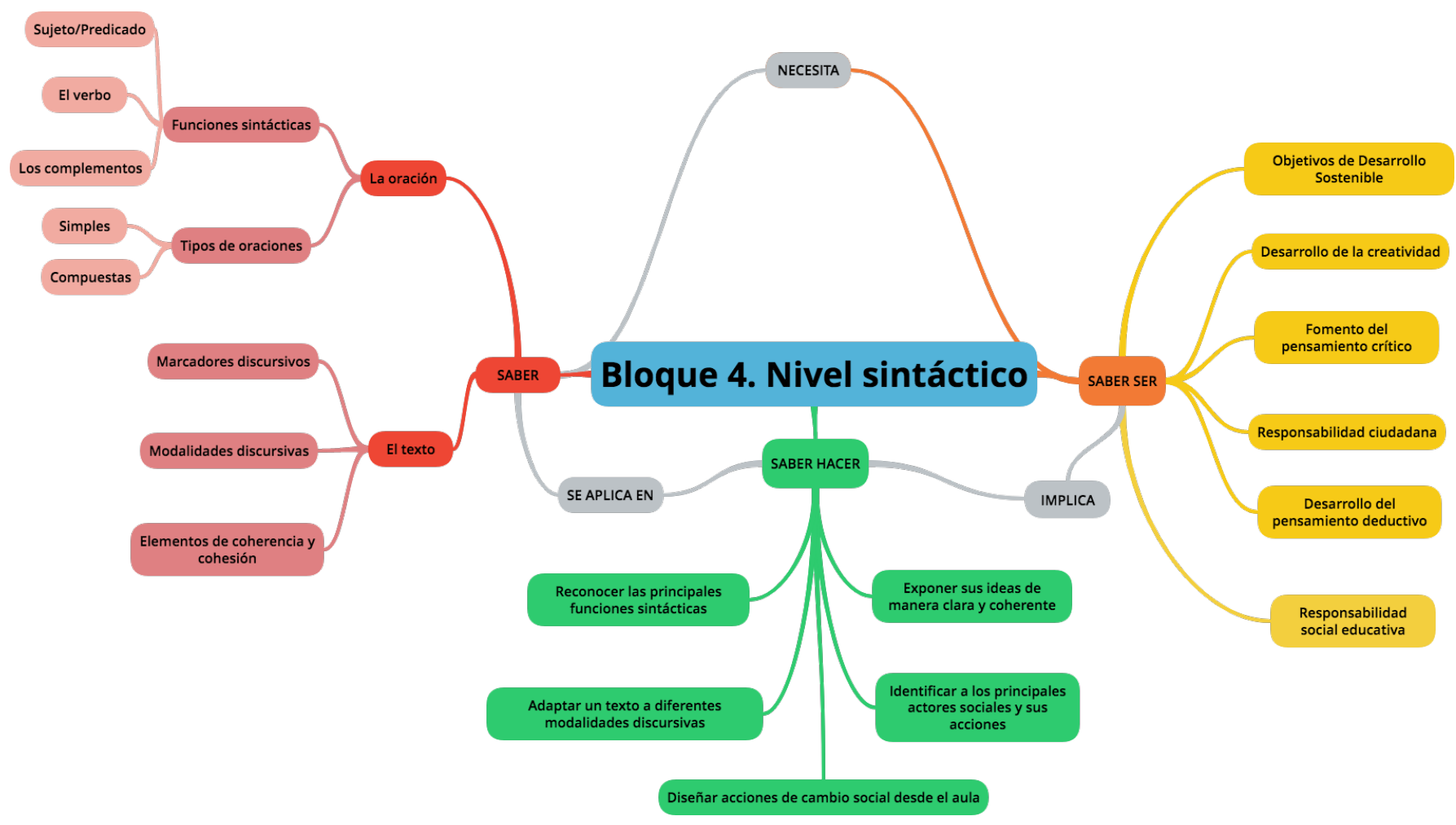

Figura 4. Mapa de contenidos Bloque 4. Nivel sintáctico

Jornadas de Formación e Innovación Docente del Profesorado | № 2 (2019) 
A partir de estos podemos establecer un mapa de la asignatura en tres niveles: 1) (en rojo), nombres de los bloques; 2) (en azul), contenido aglutinador del tema y 3) (en verde), preguntas clave, que serán las que se usarán para las escaleras de aprendizaje. Hemos añadido un cuarto nivel (en naranja), trabajado de manera transversal.

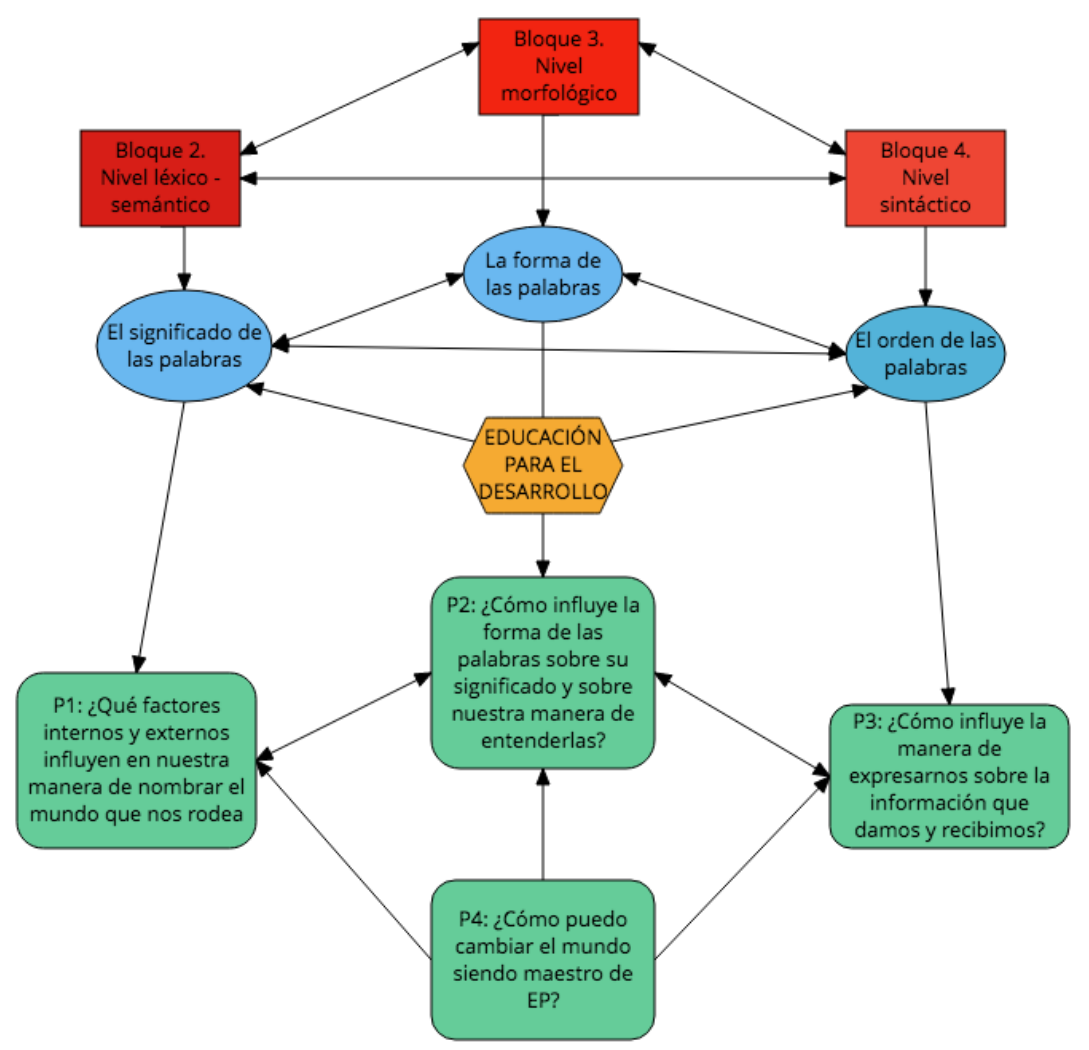

Figura 5. Relación de preguntas clave

\section{Modelo metodológico y secuencia de actividades programadas}

Para establecer el modelo metodológico hemos partido del CIMA anterior, centrado en la unificación de teoría y práctica. Destaca la aplicación de dinámicas cuyo objetivo es una ruptura de la rutina de pensamiento,

Jornadas de Formación e Innovación Docente del Profesorado | № 2 (2019) 
fomentando el desarrollo del pensamiento crítico. Este proceso se completa con la eliminación de las explicaciones directas, optando por la presentación de una serie de preguntas reflexivas para trabajar en grupos reducidos y de las que los alumnos extraen los aprendizajes de manera autónoma para ponerlos en común en grupo grande. Todos los contenidos son los propios de la asignatura, quedando recogidos en una diapositiva final en la que se dan los nombres terminológicos, completando un mapa de contenidos que ha ido aumentando en cada sesión.

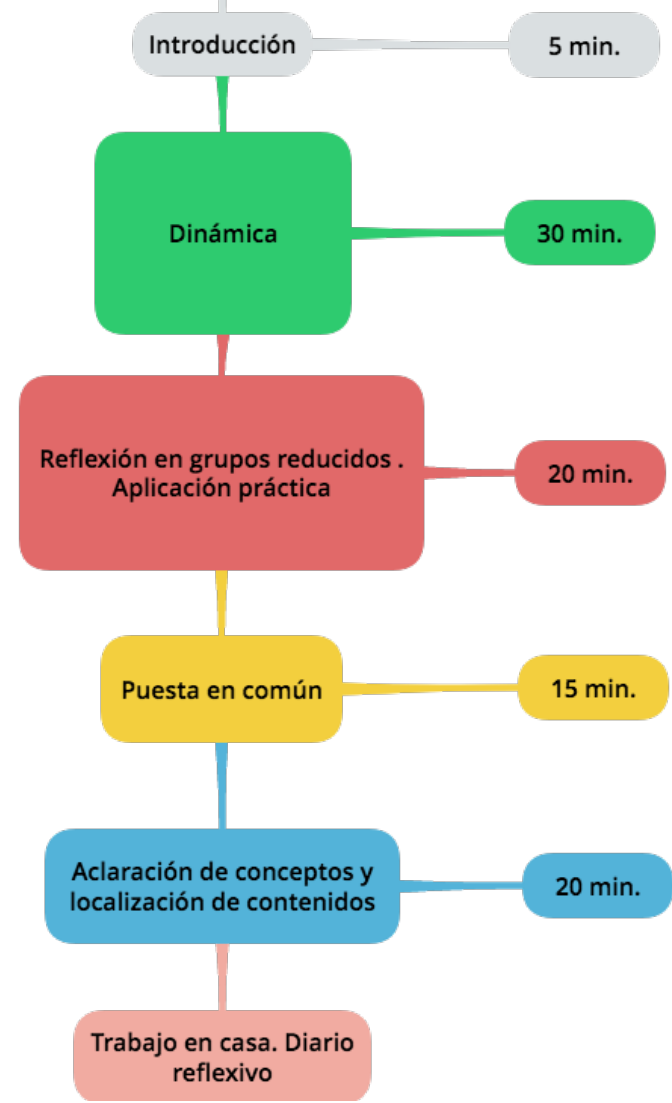

Figura 6. Modelo metodológico 2019/2020.

Se presenta a continuación la planificación inicial de las sesiones, incluyendo: las preguntas clave (en gris), que serán las que se presenten al principio y al final del CIMA y

Jornadas de Formación e Innovación Docente del Profesorado | № 2 (2019)

Esta obra se distribuye con la licencia Creative Commons 
que quedarán recogidas en las escaleras de aprendizaje; la dinámica que marca el desarrollo de la sesión y a partir de la cual reflexionan de manera autónoma los alumnos (en verde); los contenidos trabajados (en azul), señalando los que son conceptuales (C) y procedimentales $(P)$ y los temas transversales (en amarillo), que corresponderían a los contenidos actitudinales. Se han añadido además los momentos de reflexión clave (en rojo), ya que forman parte de la evaluación.

Jornadas de Formación e Innovación Docente del Profesorado | № 2 (2019)

Esta obra se distribuye con la licencia Creative Commons 
La lengua como elemento modelador del mundo que nos rodea: experiencias de Aprendizaje Servicio en la asignatura de Lengua Española y su Didáctica

CONCEPCIÓN TORRES BEGINES

Tabla 1. Secuencia de actividades del ciclo de mejora

\begin{tabular}{|c|c|c|c|c|c|}
\hline so & S1 & S2 & S3 & S4 & S5 \\
\hline $26 / 9$ & $30 / 9$ & $1 / 10$ & $3 / 10$ & $7 / 10$ & $8 / 10$ \\
\hline \multirow[t]{3}{*}{$\begin{array}{c}\text { Preguntas iniciales } \\
\text { escalera de aprendizaje }\end{array}$} & $\begin{array}{c}\text { P4: ¿Cómo puedo cambiar } \\
\text { el mundo siendo maestro } \\
\text { de EP? }\end{array}$ & $\begin{array}{l}\text { P1: ¿Qué factores } \\
\text { internos y externos } \\
\text { influyen en nuestra } \\
\text { manera de nombrar el } \\
\text { mundo que nos rodea? }\end{array}$ & $\begin{array}{l}\text { P1: ¿Qué factores } \\
\text { internos y externos } \\
\text { influyen en nuestra } \\
\text { manera de nombrar el } \\
\text { mundo que nos rodea? }\end{array}$ & $\begin{array}{l}\text { P4: ¿Cómo puedo } \\
\text { cambiar el mundo } \\
\text { siendo maestro de EP? }\end{array}$ & $\begin{array}{l}\text { P1: ¿Qué factores } \\
\text { internos y externos } \\
\text { influyen en nuestra } \\
\text { manera de nombrar el } \\
\text { mundo que nos rodea? }\end{array}$ \\
\hline & $\begin{array}{l}\text { Visita ONGs: Claver y } \\
\text { Solidaridad Don Bosco } \\
\text { Las Las ONGs presentan } \\
\text { los proyectos en los que } \\
\text { los alumnos podrán } \\
\text { participar con sus diseños } \\
\text { de ApS. }\end{array}$ & $\begin{array}{c}\text { La poesía visual de } \\
\text { Chema Madoz } \\
\text { Trabajamos los } \\
\text { conceptos de significado } \\
\text { y significante con una } \\
\text { dinámica de titulación } \\
\text { de las imágenes de } \\
\text { Chema Madoz. }\end{array}$ & $\begin{array}{l}\text { Ugur Gallen: Universo } \\
\text { Paralelo } \\
\text { Trabajamos los } \\
\text { conceptos de sema } \\
\text { y semema con los } \\
\text { fotomontajes de Ugur } \\
\text { Gallen. }\end{array}$ & $\begin{array}{l}\text { Visita ONGs: Tiritas } \\
\text { Creativas y Madre } \\
\text { Coraje } \\
\text { Las ONGs presentan los } \\
\text { proyectos en los que } \\
\text { los alumnos podrán } \\
\text { participar con sus } \\
\text { diseños de ApS. }\end{array}$ & $\begin{array}{l}\text { Angelika Dass: Humanae } \\
\text { Project } \\
\text { Reflexionamos sobre el } \\
\text { concepto de color carne } \\
\text { con una conferencia de } \\
\text { Angelika Dass. } \\
\text { Repasamos los } \\
\text { conceptos de } \\
\text { significante, significado, } \\
\text { sema, semema y los } \\
\text { factores. }\end{array}$ \\
\hline & & $\begin{array}{l}\text { Bloque 2. Los } \\
\text { componentes (C). } \\
\text { Identificar los } \\
\text { procedimientos } \\
\text { mentales }(\mathrm{P})\end{array}$ & $\begin{array}{l}\text { Bloque 2. Los } \\
\text { componentes (C). } \\
\text { Identificar los } \\
\text { procedimientos } \\
\text { mentales }(\mathrm{P})\end{array}$ & & $\begin{array}{c}\text { Bloque 2. Los } \\
\text { componentes y } \\
\text { las disciplinas }(\mathrm{C}) \text {. } \\
\text { Reconocer los factores } \\
\text { externos que influyen } \\
\text { en el significado de las } \\
\text { palabras }(\mathrm{P})\end{array}$ \\
\hline
\end{tabular}

Jornadas de Formación e Innovación Docente del Profesorado | № 2 (2019) 
La lengua como elemento modelador del mundo que nos rodea: experiencias de Aprendizaje Servicio en la asignatura de Lengua Española y su Didáctica

CONCEPCIÓN TORRES BEGINES

\begin{tabular}{|c|c|c|c|c|c|}
\hline & Otra realidad local & $\begin{array}{l}\text { Fomento de la } \\
\text { creatividad y el } \\
\text { pensamiento crítico. }\end{array}$ & $\begin{array}{l}\text { Otras realidades: guerra } \\
\text { de Siria, migración. }\end{array}$ & Otra realidad local & $\begin{array}{l}\text { El color de la piel como } \\
\text { elemento de racismo }\end{array}$ \\
\hline $\begin{array}{l}\text { Reflexión sobre uno } \\
\text { mismo: ¿quién soy yo? } \\
\text { ¿cuál es mi lugar en la } \\
\text { sociedad? ¿puedo ser } \\
\text { agente de cambio? }\end{array}$ & $\begin{array}{l}\text { Reflexión sobre la } \\
\text { realidad y el servicio: } \\
\text { ¿cómo me hace sentir lo } \\
\text { que he escuchado hoy? } \\
\text { ¿qué podría hacer yo para } \\
\text { cambiar esa realidad? }\end{array}$ & & & $\begin{array}{c}\text { Reflexión sobre la } \\
\text { realidad y el servicio: } \\
\text { ¿cómo me hace sentir } \\
\text { lo que he escuchado } \\
\text { hoy? ¿qué podría hacer } \\
\text { yo para cambiar esa } \\
\text { realidad? }\end{array}$ & \\
\hline S6 & S7 & S8 & S9 & $\mathrm{S} 10$ & S11 \\
\hline $10 / 10$ & $14 / 10$ & $15 / 10$ & $17 / 10$ & $21 / 10$ & $22 / 10$ \\
\hline $\begin{array}{l}\text { P1: ¿Qué factores } \\
\text { internos y externos } \\
\text { influyen en nuestra } \\
\text { manera de nombrar el } \\
\text { mundo que nos rodea? }\end{array}$ & $\begin{array}{l}\text { P1: ¿Qué factores internos } \\
\text { y externos influyen } \\
\text { en nuestra manera de } \\
\text { nombrar el mundo que } \\
\text { nos rodea? }\end{array}$ & $\begin{array}{c}\text { P4: ¿Cómo puedo } \\
\text { cambiar el mundo } \\
\text { siendo maestro de EP? }\end{array}$ & $\begin{array}{l}\text { P2: ¿Cómo influye la } \\
\text { forma de las palabras } \\
\text { sobre su significado y } \\
\text { sobre nuestra manera } \\
\text { de entenderlas? }\end{array}$ & $\begin{array}{l}\text { P2: ¿Cómo influye la } \\
\text { forma de las palabras } \\
\text { sobre su significado y } \\
\text { sobre nuestra manera } \\
\text { de entenderlas? }\end{array}$ & $\begin{array}{l}\text { P2: ¿Cómo influye la } \\
\text { forma de las palabras } \\
\text { sobre su significado y } \\
\text { sobre nuestra manera } \\
\text { de entenderlas? }\end{array}$ \\
\hline
\end{tabular}

Jornadas de Formación e Innovación Docente del Profesorado | № 2 (2019)

(c) $(1) \odot$ Esta obra se distribuye con la licencia Creative Commons Reconocimiento-NoComercial-SinObraDerivada Internacional (CC BY-NC-ND 4.0.) 


\begin{tabular}{|c|c|c|c|c|c|}
\hline $\begin{array}{l}\text { El curioso origen de las } \\
\text { palabras. Aprendemos } \\
\text { las diferentes partes } \\
\text { de la entrada del } \\
\text { diccionario buscando el } \\
\text { significado de términos } \\
\text { que no conocemos, pero } \\
\text { que designan realidades } \\
\text { cercanas, como el } \\
\text { nombre de la espuma } \\
\text { de la cerveza. }\end{array}$ & $\begin{array}{l}\text { ¿Quién soy? ¿De dónde } \\
\text { vengo? ¿A dónde voy? } \\
\text { Bruno Catalano, Traveler } \\
\text { A través de imágenes de } \\
\text { migrantes de diferentes } \\
\text { países y momentos } \\
\text { históricos, reflexionamos } \\
\text { sobre el movimiento } \\
\text { migratorio, su campo } \\
\text { semántico y su familia } \\
\text { léxica. }\end{array}$ & $\begin{array}{c}\text { Análisis de } \\
\text { publicaciones en redes } \\
\text { sociales sobre los } \\
\text { temas tratados. } \\
\text { A partir de } \\
\text { publicaciones de } \\
\text { nuestras propias redes } \\
\text { sociales, detectamos } \\
\text { el campo semántico, la } \\
\text { familia léxica, etc. } \\
\text { Diseño del proyecto } \\
\text { de Aps. }\end{array}$ & $\begin{array}{c}\text { Fundeu BBVA: La } \\
\text { palabra del año } \\
\text { Analizamos la formación } \\
\text { de las palabras } \\
\text { candidatas a palabra del } \\
\text { año } 2018\end{array}$ & $\begin{array}{l}\text { Highlight the } \\
\text { remarkable } \\
\text { A partir de la campaña } \\
\text { de rotuladores Stabilo, } \\
\text { ponemos en valor la } \\
\text { igualdad de género. } \\
\text { Analizamos la diferencia } \\
\text { de significado de } \\
\text { palabras al cambiar su } \\
\text { género. }\end{array}$ & $\begin{array}{c}\text { Story cubes } \\
\text { Mediante este juego } \\
\text { obtenemos las ideas } \\
\text { previas y presentamos } \\
\text { los principales tipos de } \\
\text { palabras }\end{array}$ \\
\hline $\begin{array}{l}\text { Bloque 2. Las disciplinas } \\
\text { (C). Reconocer los } \\
\text { factores externos que } \\
\text { influyen en el significado } \\
\text { de las palabras (P) }\end{array}$ & $\begin{array}{l}\text { Bloque 2. Las relaciones } \\
\text { (C). Establecer las } \\
\text { relaciones entre } \\
\text { las palabras por su } \\
\text { significado (P) }\end{array}$ & $\begin{array}{l}\text { Bloque 2. Las relaciones } \\
\text { (C). Establecer las } \\
\text { relaciones entre } \\
\text { las palabras por } \\
\text { su significado (P), } \\
\text { Aprendizaje Servicio (P). }\end{array}$ & $\begin{array}{l}\text { Bloque 3. Los elementos, } \\
\text { los procesos (C). } \\
\text { Identificar los elementos } \\
\text { que forman la palabra } \\
\text { (P). Procesos de } \\
\text { creación (P) }\end{array}$ & $\begin{array}{l}\text { Bloque 3. Los elementos } \\
\text { (C). Identificar los } \\
\text { elementos que forman } \\
\text { la palabra (P). }\end{array}$ & $\begin{array}{c}\text { Bloque 3. Los tipos (C). } \\
\text { Identificar los tipos de } \\
\text { palabras (P). }\end{array}$ \\
\hline \multirow{2}{*}{$\begin{array}{c}\text { La riqueza lingüística } \\
\text { del español. Valorar la } \\
\text { diferencia }\end{array}$} & Migración & $\begin{array}{c}\text { Responsabilidad social } \\
\text { universitaria. }\end{array}$ & $\begin{array}{c}\text { El lenguaje como reflejo } \\
\text { de la sociedad. }\end{array}$ & Igualdad de género & $\begin{array}{l}\text { Fomento de la } \\
\text { creatividad }\end{array}$ \\
\hline & $\begin{array}{l}\text { Reflexión sobre sobre } \\
\text { por qué llevar a cabo el } \\
\text { aprendizaje-servicio en la } \\
\text { Universidad: elección del } \\
\text { proyecto. }\end{array}$ & & & & \\
\hline $\mathrm{S} 12$ & $\mathrm{~S} 13$ & $\mathrm{~S} 14$ & $\mathrm{~S} 15$ & $\mathrm{~S} 16$ & $\mathrm{~S} 17$ \\
\hline
\end{tabular}

Jornadas de Formación e Innovación Docente del Profesorado I № 2 (2019)

cc) (1) Esta obra se distribuye con la licencia Creative Commons 
CONCEPCIÓN TORRES BEGINES

\begin{tabular}{|c|c|c|c|c|c|}
\hline $24 / 10$ & $28 / 10$ & $29 / 10$ & $31 / 19$ & $4 / 11$ & $5 / 11$ \\
\hline $\begin{array}{l}\text { P2: ¿Cómo influye la } \\
\text { forma de las palabras } \\
\text { sobre su significado y } \\
\text { sobre nuestra manera } \\
\text { de entenderlas? }\end{array}$ & $\begin{array}{c}\text { P4: ¿Cómo puedo cambiar } \\
\text { el mundo siendo maestro } \\
\text { de EP? }\end{array}$ & $\begin{array}{l}\text { P2: ¿Cómo influye la } \\
\text { forma de las palabras } \\
\text { sobre su significado y } \\
\text { sobre nuestra manera } \\
\text { de entenderlas? }\end{array}$ & $\begin{array}{l}\text { P3: ¿Cómo influye la } \\
\text { manera de expresarnos } \\
\text { sobre la información } \\
\text { que damos y recibimos? }\end{array}$ & $\begin{array}{l}\text { P3: ¿Cómo influye la } \\
\text { manera de expresarnos } \\
\text { sobre la información } \\
\text { que damos y recibimos? }\end{array}$ & $\begin{array}{l}\text { P3: ¿Cómo influye la } \\
\text { manera de expresarnos } \\
\text { sobre la información } \\
\text { que damos y recibimos? }\end{array}$ \\
\hline $\begin{array}{l}\text { Etiquetas. Presentamos } \\
\text { una imagen impactante } \\
\text { de pobreza y ponemos } \\
\text { las ideas que se nos } \\
\text { vengan a la cabeza } \\
\text { sobre la realidad que } \\
\text { vemos. Catalogamos las } \\
\text { palabras que aparecen y } \\
\text { analizamos sustantivos y } \\
\text { adjetivos. }\end{array}$ & $\begin{array}{l}\text { Dictado visual. Diseño de } \\
\text { una sesión de ApS con los } \\
\text { contenidos del bloque }\end{array}$ & $\begin{array}{c}\text { ¿Qué tengo en la } \\
\text { cabeza? } \\
\text { Repaso de todos los } \\
\text { contenidos del tema a } \\
\text { través del juego. } \\
\text { Evaluación por pares de } \\
\text { las propuestas de ApS. }\end{array}$ & $\begin{array}{c}\text { Black stories } \\
\text { Detección de las } \\
\text { principales funciones } \\
\text { sintácticas a través de } \\
\text { un juego de deducción. }\end{array}$ & $\begin{array}{l}\text { Mímica con los ODS } \\
\text { Representación } \\
\text { mediante la mímica } \\
\text { de las diferentes } \\
\text { funciones sintácticas } \\
\text { relacionándolas con } \\
\text { los ODS }\end{array}$ & $\begin{array}{l}\text { @LadyDistopia. } \\
\text { Creación de relatos a } \\
\text { partir de fotografias } \\
\text { curiosas. Análisis de los } \\
\text { principales elementos y } \\
\text { funciones sintácticas. }\end{array}$ \\
\hline $\begin{array}{c}\text { Bloque 3. Los tipos (C). } \\
\text { Identificar los tipos de } \\
\text { palabras (P). }\end{array}$ & $\begin{array}{l}\text { Bloque 3. Aprendizaje } \\
\text { Servicio en el aula } \\
\text { (P). Diseñar sesiones } \\
\text { didácticas sobre } \\
\text { morfología (P). }\end{array}$ & $\begin{array}{c}\text { Repaso de todos los } \\
\text { elementos del bloque } 3 \text {. }\end{array}$ & $\begin{array}{l}\text { Bloque 4. Las } \\
\text { funciones sintácticas } \\
\text { (C). Reconocer las } \\
\text { principales funciones } \\
\text { sintácticas (P). }\end{array}$ & $\begin{array}{l}\text { Bloque 4. Las } \\
\text { funciones sintácticas } \\
\text { (C). Reconocer las } \\
\text { principales funciones } \\
\text { sintácticas (P). }\end{array}$ & $\begin{array}{l}\text { Bloque 4. Las } \\
\text { funciones sintácticas } \\
\text { (C). Reconocer las } \\
\text { principales funciones } \\
\text { sintácticas (P). }\end{array}$ \\
\hline $\begin{array}{l}\text { Desarrollo del } \\
\text { pensamiento crítico, } \\
\text { Justicia social }\end{array}$ & $\begin{array}{l}\text { Responsabilidad social } \\
\text { universitaria. Educación } \\
\text { ciudadana. }\end{array}$ & $\begin{array}{c}\text { Desarrollo del } \\
\text { pensamiento crítico }\end{array}$ & $\begin{array}{c}\text { Desarrollo del } \\
\text { pensamiento deductivo. }\end{array}$ & $\begin{array}{l}\text { Objetivos de Desarrollo } \\
\text { Sostenible. } \\
\text { Responsabilidad } \\
\text { ciudadana }\end{array}$ & $\begin{array}{l}\text { Desarrollo de la } \\
\text { creatividad }\end{array}$ \\
\hline
\end{tabular}

Jornadas de Formación e Innovación Docente del Profesorado I № 2 (2019)

(c) (1) $\odot$ Esta obra se distribuye con la licencia Creative Commons Reconocimiento-NoComercial-SinObraDerivada Internacional (CC BY-NC-ND 4.0.) 
La lengua como elemento modelador del mundo que nos rodea: experiencias de Aprendizaje Servicio en la asignatura de Lengua Española y su Didáctica

CONCEPCIÓN TORRES BEGINES

\begin{tabular}{|c|c|c|c|c|c|}
\hline & & $\begin{array}{c}\text { Reflexión sobre el } \\
\text { contenido académico: } \\
\text { ¿cómo puedo cambiar } \\
\text { el mundo poniendo en } \\
\text { práctica los contenidos } \\
\text { de la asignatura? }\end{array}$ & & & \\
\hline $\mathrm{S} 18$ & $\mathrm{~S} 19$ & $\mathrm{~S} 20$ & & & \\
\hline $7 / 11$ & $11 / 11$ & $14 / 11$ & & & \\
\hline $\begin{array}{l}\text { P3: ¿Cómo influye la } \\
\text { manera de expresarnos } \\
\text { sobre la información } \\
\text { que damos y recibimos? }\end{array}$ & $\begin{array}{c}\text { P3: ¿Cómo influye la } \\
\text { manera de expresarnos } \\
\text { sobre la información que } \\
\text { damos y recibimos? }\end{array}$ & $\begin{array}{c}\text { Preguntas finales } \\
\text { escalera de aprendizaje }\end{array}$ & & & \\
\hline $\begin{array}{l}\text { \#FridaysforFuture. } \\
\text { Análisis del discurso } \\
\text { de la activista Greta } \\
\text { Thunberg localizando } \\
\text { los mecanismos de } \\
\text { coherencia y cohesión } \\
\text { y los marcadores del } \\
\text { discurso. }\end{array}$ & $\begin{array}{c}\text { Malala: la educación } \\
\text { puede cambiar el mundo } \\
\text { Reescritura del discurso } \\
\text { de Malala al recibir } \\
\text { el Nobel según las } \\
\text { diferentes modalidades } \\
\text { textuales. }\end{array}$ & & & & \\
\hline
\end{tabular}

Jornadas de Formación e Innovación Docente del Profesorado | № 2 (2019) 
La lengua como elemento modelador del mundo que nos rodea: experiencias de Aprendizaje Servicio en la asignatura de Lengua Española y su Didáctica

CONCEPCIÓN TORRES BEGINES

\begin{tabular}{|c|c|}
\hline $\begin{array}{l}\text { Bloque 3. El texto (C). } \\
\text { Exponer sus ideas } \\
\text { de manera clara y } \\
\text { coherente (P). Identificar } \\
\text { a los principales } \\
\text { actores sociales y sus } \\
\text { acciones (P) }\end{array}$ & $\begin{array}{l}\text { Bloque 3. El texto (C). } \\
\text { Adaptar un texto a } \\
\text { diferentes } \\
\text { modalidades discursivas } \\
\text { (P). Identificar a los } \\
\text { principales } \\
\text { actores sociales y sus } \\
\text { acciones (P). Diseñar } \\
\text { acciones de cambio social } \\
\text { desde el aula (P). }\end{array}$ \\
\hline \multirow[t]{2}{*}{$\begin{array}{c}\text { Desarrollo de la } \\
\text { creatividad }\end{array}$} & $\begin{array}{c}\text { Fomento del } \\
\text { pensamiento crítico. } \\
\text { Educación ciudadana }\end{array}$ \\
\hline & $\begin{array}{c}\text { Reflexión sobre la } \\
\text { profesión: ¿qué puedo } \\
\text { hacer como profesional } \\
\text { de la educación para } \\
\text { cambiar el mundo? }\end{array}$ \\
\hline
\end{tabular}

Jornadas de Formación e Innovación Docente del Profesorado | № 2 (2019)

cc (7) $\odot$ Esta obra se distribuye con la licencia Creative Commons

Reconocimiento-NoComercial-SinObraDerivada 


\section{Diario de las sesiones}

Día 1. Iniciamos el primer bloque del ciclo de mejora (nivel léxico-semántico) exponiendo unas fotografias de Chema Madoz a las que los alumnos debían ponerles título. Una vez tituladas de manera individual, trabajaron en pequeños grupos poniendo en común las respuestas que habian dado y detectando las diferencias. Para guiar el trabajo se proyectó una serie de preguntas centradas en los factores que influyen en su manera de nombrar las cosas. Este primer día se detectó cierto desconcierto entre los alumnos, que no terminaban de ver la relación entre las dinámicas y los contenidos propios de la asignatura, pero se les animó en todo momento a confiar en la planificación establecida.

Día 2. Esta sesión estuvo dinamizada por dos ONGs locales: Claver y Solidaridad Don Bosco, quienes presentaron sus proyectos para que los alumnos pudieran elegir en los que querian trabajar. Fue interesante porque trataron temas como los movimientos migratorios, la dignidad laboral y algunos conceptos de Educación para el Desarrollo, temas transversales en cualquier formación y que los alumnos tienen pocas oportunidades para aprender. La acogida, por lo que fuimos viendo en los diarios reflexivos, fue muy buena, ya que les hizo repensar situaciones que tienen a su alrededor y que reconocieron en los ejemplos dados.

Día 3. Trabajamos a partir de los fotomontajes de Ugur Gallen, en los que superpone imágenes de contextos acomodados y desfavorecidos. Como dinámica inicial, le dimos a los alumnos una serie de palabras presentes en su entorno cotidiano: bañera, niño, niña, escuela... y de manera individual pensaban en una imagen mental. A continuación, en grupos, pusieron en común los resultados, debiendo elaborar una definición en un tiempo dado. A continuación, en grupo grande, construimos las

Jornadas de Formación e Innovación Docente del Profesorado | № 2 (2019)

Esta obra se distribuye con la licencia Creative Commons 
definiciones de cada palabra, detectando los semas y los sememas. A cada una le contrapusimos uno de los montajes, llamando además la atención sobre el hecho de que los semas son los mismos en ambos contextos y que lo que cambia es el significado que nosotros le damos. La respuesta de los alumnos fue muy positiva, destacando la inclusión de estos valores. Además, los tiempos concretos facilitaron un mejor aprovechamiento de la sesión

Día 4. Esta sesión estuvo dinamizada por las dos ONGs que faltaban: Madre Coraje y Tiritas Creativas. En esta ocasión fueron presentaciones más dinámicas que las dos anteriores, presentando unos proyectos más de interacción directa con los beneficiarios.

Día 5. Comenzamos con una dinámica en la que los alumnos debían encontrar a algún compañero que tuviera su mismo color de piel. Pasado el tiempo asignado, debatimos si habían encontrado a alguien, llegando a la conclusión de que es una misión imposible a pesar de estar todos dentro de la denominada raza blanca, jugando así con significante (blanco) y significado (los diferentes tonos de piel). A continuación, se proyectó una conferencia a cargo de Angelica Dass, responsable del Humanae Project, en el que se reflexiona sobre los tonos de piel y las razas. Esta actividad se completó con una serie de preguntas a las que debían dar respuesta aplicando los resultados obtenidos en la primera actividad, el vídeo y los contenidos previos. Por último, introdujimos el concepto de Lexicología. Esta sesión fue de la más exitosas, según se plasmó en los diarios, destacando sobre todo la posibilidad de tener que establecer un diálogo con los compañeros para averiguar el color de piel. En muchas ocasiones damos por hecho que los alumnos se conocen, pero agradecen este tipo de oportunidades.

Día 6. Partimos de la presentación de una serie de palabras con un origen etimológico curioso. A continuación, Jornadas de Formación e Innovación Docente del Profesorado | № 2 (2019) 
propusimos una serie de preguntas sobre la definición de diccionario, su utilidad y los tipos, creando entre todos los contenidos conceptuales. La actividad principal consistió en buscar en el diccionario dieciséis palabras relacionadas con su entorno, pero cuyo nombre desconocían, como giste (espuma de la cerveza) o escrupulillo (bolita de metal de los cascabeles). Para finalizar, y como actividad de asentamiento, se definieron las diferentes partes de la entrada del diccionario, tomando como referencia el trabajo realizado previamente. En esta sesión destacamos que los alumnos comenzaron a comprender la dinámica de la clase, viendo que los contenidos presentados no son algo aislado y sin aparente relación con el área de Lengua, sino que se pueden usar ejemplos atractivos sin que eso suponga un aprendizaje menor.

Día 7. A partir de los movimientos migratorios trabajamos el campo semántico, la familia léxica y algunos fenómenos léxicos. Para iniciar la sesión introdujimos un cambio en los materiales programados inicialmente para recoger la sugerencia de una alumna sobre el visionado del videoclip de la canción Guerra del cantante Residente y que utilizamos para establecer el concepto de campo semántico. Retomamos después la programación original, trabajando a partir de imágenes de diferentes épocas, las esculturas de Bruno Catalano de la serie Traveler y preguntas reflexivas los conceptos de emigrante, inmigrante y migrante, añadiendo además los de expatriado y exiliado para trabajar la sinonimia y la antonimia. Siguiendo este hilo y haciendo referencia a la comida como uno de los elementos esenciales de la identidad, presentamos algunas imágenes para explicar la polisemia (judías verdes y judías blancas o chícharos) y la monosemia (aceituna).

Día 8. Comenzamos con un repaso de los contenidos aprendidos hasta ahora para comprobar la adquisición real de los conceptos a pesar de hacer uso de una metodología diferente. Para ello, les invitamos a buscar entre

Jornadas de Formación e Innovación Docente del Profesorado | № 2 (2019)

Esta obra se distribuye con la licencia Creative Commons 
sus publicaciones en redes sociales alguna que tratase alguno de los temas transversales presentados, analizándolas en base a los contenidos previos. En una segunda parte, con una rejilla para el diseño de proyectos de ApS, y mezclando los grupos de manera que no hubiese grupos uniformes, trabajamos sobre necesidades detectadas aplicando los contenidos del bloque 2. En los diarios pudimos apreciar una aceptación creciente entre el alumnado, quien valora el encadenamiento de los contenidos y la constante puesta en práctica como un aspecto positivo.

Día 9. En base a los datos recogidos el día anterior, detectamos que hay una necesidad de profundizar en la metodología del ApS, por lo que comenzamos la clase proyectando un video de Roser Batllé donde se explica el concepto y se dan algunos ejemplos. A continuación, usamos la red social Instagram y la cuenta Eh!Universo, donde se recogen un vídeos sobre temáticas sociales actuales. Cada grupo eligió un vídeo y detectó su necesidad social, las posibles actuaciones desde el aula y la necesidad educativa, entendida esta como el aprendizaje necesario para llevar a cabo esas actuaciones. En una segunda parte retomamos la programación, centrada en los procesos de formación de palabras y sus tipos, con la campaña de la Fundeu "La palabra del año" haciendo un recorrido por las más recientes, como microplástico, aporofobia o escrache, explicando su significando y detectando entre todos los procesos de formación. Aunque esta actividad estaba pensada para grupos reducidos, la inclusión de la primera parte hizo que fuera necesaria una adaptación que dejó poco tiempo para lo planificado inicialmente, pero, como pudimos comprobar posteriormente, esta parada para fijar las bases de la metodología fue de gran utilidad.

Día 10. Partiendo de la campaña de Stabilo Highlight the remarkable en la que se presenta a las mujeres que están detrás de algunos grandes logros de la humanidad, presentamos algunos casos de mujeres españolas exitosas

Jornadas de Formación e Innovación Docente del Profesorado | № 2 (2019)

Esta obra se distribuye con la licencia Creative Commons 
y a los hombres que las ayudaron a triunfar en sus respectivos campos. Valorando además la buena acogida de los recursos audiovisuales presente en los diarios, incluimos en la programación el discurso de Emma Watson en la ONU sobre el proyecto \#HeforShe. Tras una puesta en común para aclarar los conceptos de género gramatical y sus tipos, pasamos a proyectar una serie de diapositivas en las que aparecía una palabra en género masculino y femenino con su correspondiente significado visual. Este es el caso por ejemplo de zorro, significante compartido tanto para zorro macho como para hembra, lo que hemos hecho notar con la proyección de la misma imagen de un cachorro en las dos ocasiones, jugando así con los significados de ciertas palabras en género femenino. Para completar la reflexión, buscamos otros ejemplos similares y concluyendo que el género influye sobre nuestra manera de percibir las palabras. En esta sesión destacó un alumno que se acercó para matizar que es la primera vez que siente que está aprendiendo algo, ya que, aunque no está adquiriendo nuevos contenidos sobre la Lengua Española (son de repaso), si está aprendiendo más sobre la actualidad y sobre cómo llevarla a su futura aula.

Día 11. Iniciamos la clase con un vídeo introductorio sobre dos historias del pensamiento lateral, utilizándolas como excusa para animar a los alumnos a pensar por sí mismos. A continuación, trabajamos con los Story Cubes para obtener dos palabras que tenían que introducir en una historia con un marco muy particular: cuatro selfis tomados la semana previa en Barcelona. Pasado el tiempo asignado, pusimos en común una historia para cada una de las fotos, incluyendo las palabras extra además de un concepto, una acción, un adjetivo, un tiempo, un espacio, una cantidad. Haciendo uso de las historias y analizando la presencia de estos contenidos repasamos los tipos de palabras. Para finalizar, propusimos un pequeño debate sobre las noticias y la creación de opiniones propias sobre los altercados de Barcelona haciendo hincapié en la

Jornadas de Formación e Innovación Docente del Profesorado | № 2 (2019)

Esta obra se distribuye con la licencia Creative Commons 
aparición de bulos y noticias falsas, dando como ejemplo la actividad realizada a partir de imágenes reales. Cerramos con un vídeo de Maldita, una web especializada en la detección de bulos.

Día 12. Nos centramos en los tipos de sustantivos y adjetivos como contenido conceptual y la igualdad de género como tema transversal. Aunque inicialmente la dinámica "Etiquetas" estaba pensada para trabajar la pobreza, nos decantamos por el tema de la igualdad ya que en sesiones anteriores los alumnos presentaron un elevado interés y el cambio de tema no influía en la adquisición de los contenidos. Con este fin proyectamos dos imágenes de mujeres: un ama de casa y una ejecutiva, animando a los alumnos a escribir en la pizarra las palabras que se les viniesen a la cabeza, repitiendo la actividad con dos hombres en la misma actitud. Iniciamos entonces un debate sobre las ideas que se tienen de uno y otro, completándolo además con algunos titulares de periódicos en los que está presente la desigualdad de género.

Día 13. Por una cuestión de agenda de las ONGs, la sesión que estaba pensada para hoy pasó a ser la sesión inicialmente 14. Para no perder la dinámica del día, basada en el juego Dime quién soy, en la que los alumnos debian averiguar sus palabras haciendo preguntas sobre su tipo: variable/invariable, común/propio, etc. se incluyó en esta sesión. A continuación, retomamos la planificación con Black Stories, un juego de cartas en el que a partir de un relato hay que averiguar lo que ha ocurrido. Esta dinámica, que ocupó toda la sesión, nos sirvió para presentar contenidos del cuarto bloque (nivel sintáctico), incluyendo las principales funciones sintácticas.

Días 14 y 15. Estos dos días se centraron en el diseño de los Proyectos de ApS y en la detección de necesidades. Para ello contamos con la presencia de las ONGs que iban a recibir a los alumnos, trabajando como moderadores y guías del trabajo.

Jornadas de Formación e Innovación Docente del Profesorado | № 2 (2019)

Esta obra se distribuye con la licencia Creative Commons 
Día 16. Retomamos de nuevo el tema de la sintaxis con una dinámica centrada en el Aprendizaje Basado en Juego y los Objetivos de Desarrollo Sostenible. Tras una reflexión inicial sobre el tema, pensamos una palabra de cada tipo relacionada con los ODS, mezclándose las presentadas por el grupo en cuatro categorías: verbo, sustantivo, adjetivo y adverbio. Por turnos, cada integrante debía coger una palabra de cada categoría, formar una oración y representarla ante el resto del grupo a través de la mímica, reconociendo todas funciones sintácticas. Esta dinámica, aunque muy popular, no dejó satisfecha a parte de la clase porque esperaban repasar los contenidos sintácticos de manera más teórica. Nos llamó la atención que, aunque otros contenidos presentados eran más novedosos (los referidos al tema de la semántica) es en estos, más conocidos, en los que han presentado mayores dificultades, pidiendo expresamente que se hiciera un repaso teórico y se dieran más ejemplos concretos.

Día 17. Partiendo del problema presentado en los diarios respecto a la sesión anterior, abrimos esta sesión con el perfil de Instagram de @ladydistopia, donde se mezclan imágenes curiosas y creación literaria. En primer lugar, proyectamos varias de las historias del perfil para pasar luego a una dinámica individual en la que cada uno debía elegir una de las imágenes y crear una historia breve, analizando después los tipos de oraciones.

Días 18 y 19. Quisimos cerrar el CIMA poniendo como ejemplo final a dos niñas que están revolucionando el mundo. Greta Thunberg y su campaña \#FridaysforFuture y Malala, defensora de la educación como motor de cambio. En ambas sesiones seguimos una dinámica de proyección de un vídeo sobre sus discursos en la ONU y al recoger el Nobel y un trabajo en grupo sobre los mismos discursos escritos, detectando los elementos de coherencia, cohesión y los marcadores discursivos y las tipologías textuales. Además, para cerrar el ciclo y enlazarlo con la

Jornadas de Formación e Innovación Docente del Profesorado | № 2 (2019)

Esta obra se distribuye con la licencia Creative Commons 
idea de cambiar el mundo desde las aulas, completamos el programa inicial con una actividad basada en la metodología ECO, centrada en el prototipado haciendo uso de unos tacos de madera de colores de una acción concreta para trabajar por un mundo mejor en el aula. La inclusión de materiales táctiles, no planificada en un principio, tuvo mucho éxito y se plantea la posibilidad de usarlos en sesiones posteriores.

\section{Evolución del aprendizaje de los estudiantes y evaluación del ciclo de mejora}

Se muestran a continuación los resultados obtenidos en las encuestas realizadas antes y después de la aplicación del ciclo de mejora. Para facilitar la lectura se han marcado en gris las respuestas obtenidas de las iniciales y en naranja las finales.

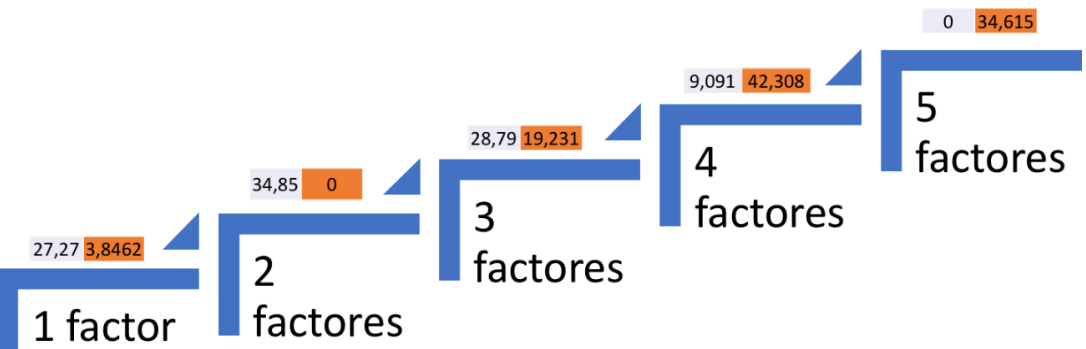

Figura 7. P1 ¿Qué factores internos y externos influyen en nuestra manera de nombrar el mundo que nos rodea?

$13,6 4 \longdiv { 3 6 , 5 3 8 }$

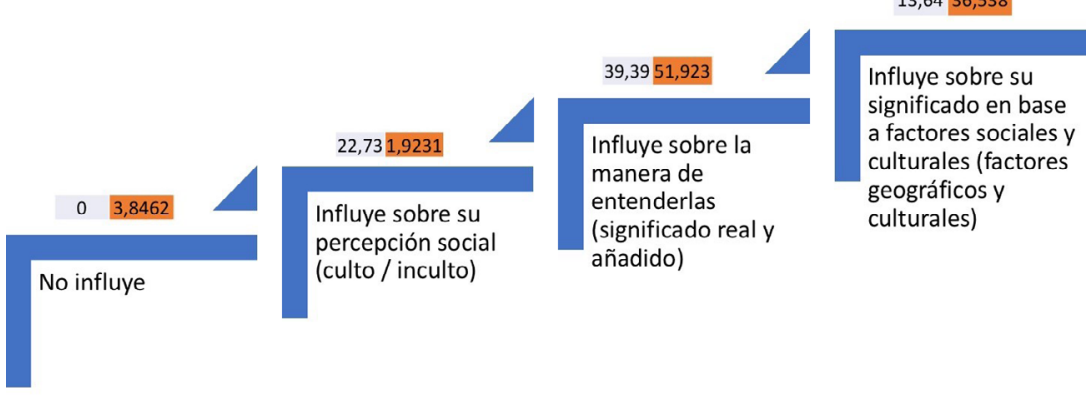

Figura 8. P2 ¿Cómo influye la forma de las palabras sobre su significado y sobre nuestra manera de entenderlas?

Jornadas de Formación e Innovación Docente del Profesorado | № 2 (2019) 


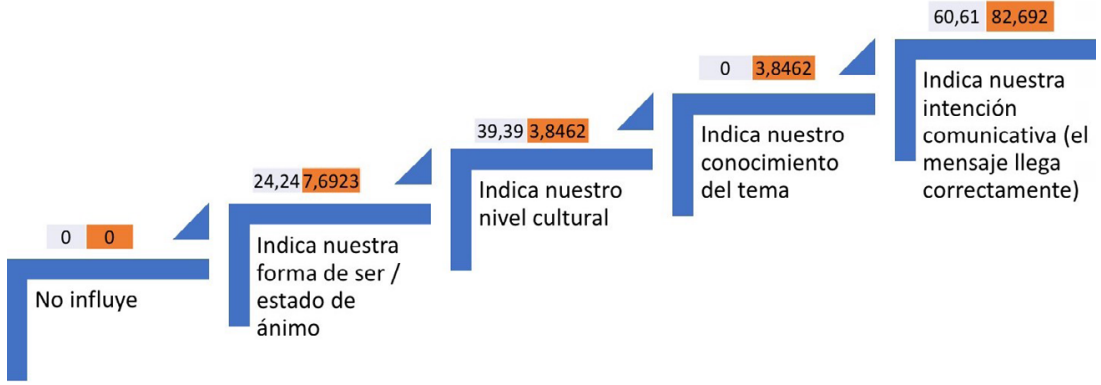

Figura 9. P3 ¿Cómo influye la manera de expresarnos sobre la información que damos y recibimos?

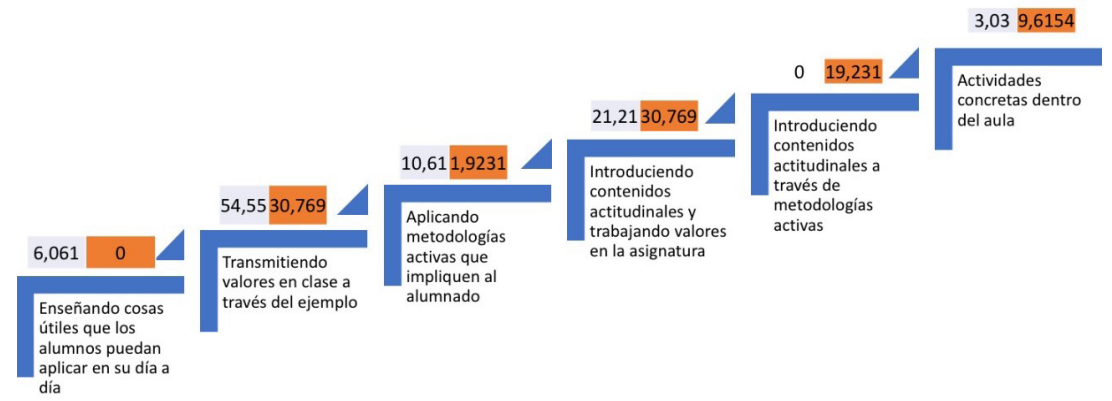

Figura 10. P4 ¿Cómo puedo cambiar el mundo siendo maestro de EP?

En general, en todas ellas ha habido un progreso hacia la respuesta más cercana a lo que se quería transmitir, apareciendo elementos que no estaban inicialmente. En el caso de la primera pregunta, se puede apreciar un claro aumento del número de factores, aspecto que queda también recogido en la segunda, donde se le da un peso específico a la influencia exterior. En la segunda y la tercera escalera llama la atención la percepción inicial de la lengua como un elemento de cultura relacionado con el nivel social que se ha ido diluyendo para dar lugar a la influencia de elementos externos independientes y más centrados en la intención comunicativa, integrando además el valor añadido.

Un caso particular es el de la cuarta, donde, por una parte, encontramos un progreso con la matización del uso de metodologías activas y el peso específico de los valores

Jornadas de Formación e Innovación Docente del Profesorado | № 2 (2019)

Esta obra se distribuye con la licencia Creative Commons 
actitudinales y, por otro, un estancamiento en el segundo y cuarto nivel, centrados en la transmisión de valores a través del ejemplo y la introducción de contenidos actitudinales, sin aplicación real, que era lo que se buscaba. Esto nos lleva a pensar que los alumnos han tomado como modelo la asignatura de Lengua Española y su Didáctica, pero desde la perspectiva del discente, no siendo capaces de trasladarlo a acciones concretas en su futuro. Frente a los resultados obtenidos en el CIMA del curso pasado, en el que estos valores sí variaban de manera significativa, concretándose en el planteamiento de actividades, parece que, en esta ocasión, esa aplicabilidad ha quedado en suspenso. Como posible causa, teniendo en cuenta esta diferencia tan significativa, podemos intuir la necesidad de matizar las respuestas de los alumnos con ellos, proyectando los resultados obtenidos y planteando nuevas preguntas, completando así un proceso que aquí queda inconcluso y que se ha dado por hecho.

Además de las escaleras de aprendizaje, hemos contado con otros instrumentos para evaluar el aprendizaje de los alumnos y nuestro propio proceso de enseñanza:

El diario grupal semanal, con un valor del 10\% sobre la nota final, y centrado en la respuesta a cuatro preguntas clave: 1) ¿qué habéis aprendido esta semana?, 2) ¿qué os gustaría haber aprendido?, 3) ¿qué cambiaríais? Y 4) ¿qué dejaríais igual? nos ha servido para contribuir a la evaluación continua del alumnado, ya que se han ido planteando diferentes problemáticas que pasan desapercibidas en el día a día. Por ejemplo, por los diarios semanales hemos podido comprobar que, aunque al principio costó un poco ver la relación entre las temáticas propuestas y los contenidos teóricos de la asignatura, los alumnos fueron cogiendo el ritmo y agradecen este tipo de metodología, siendo una constante positiva la construcción de los aprendizajes como algo dinámico e individual. Así, las dificultades detectadas en un primer momento

Jornadas de Formación e Innovación Docente del Profesorado | № 2 (2019)

Esta obra se distribuye con la licencia Creative Commons 
(desorientación, nerviosismo y dudas) han ido desapareciendo con el tiempo, ya que los alumnos han ido comprobando la adquisición efectiva de los contenidos y la continuidad de la metodología.

El diario reflexivo individual, con un valor del $20 \%$ sobre la nota final, ha buscado fomentar el desarrollo del pensamiento crítico y la reflexión sobre la función de agente de cambio social y educativo del alumnado a lo largo del proceso de realización del proyecto de ApS. Este instrumento se desgrana en una serie de reflexiones, de acuerdo con Escofet y Rubio (2017, p. 85): 1) sobre el servicio, 2) sobre uno mismo, 3) sobre la profesión, 4) sobre el contenido académico, 5) sobre por qué llevar a cabo proyectos de ApS en la universidad. En nuestro caso, las hemos desgranado en 10 entradas, de las cuales se incluyen 6 en el tiempo que abarca el ciclo de mejora y que han sido marcadas en el cronograma. A partir de su lectura hemos podido percibir un desarrollo del pensamiento crítico y una puesta en valor de la realidad local diaria a la que se enfrentan los alumnos, aunque falte (como se percibe en la escalera cuatro) el establecimiento de una relación entre lo que aprenden en clase y su futura labor como docentes capacitados para cambiar el mundo desde las aulas. De igual manera, en los diarios queda recogido el incremento en su capacidad para detectar las necesidades sociales de su entorno, aunque aún falte un paso más hacia su relación con las necesidades educativas.

El portafolio, con un valor del 30\% sobre la nota final, está dividido en dos partes: diseño previo del proyecto y memoria de la aplicación. En el ciclo de mejora se han incluido algunas sesiones centradas en la primera, además de comenzar a adentrarnos en la fase de prototipado. En general, han sido actividades muy bien acogidas que han ayudado al alumnado en su autoevaluación, permitiéndonos apreciar de manera palpable el progreso. Esto se

Jornadas de Formación e Innovación Docente del Profesorado | № 2 (2019)

Esta obra se distribuye con la licencia Creative Commons 
completará con la evaluación por parte de la ONG, con un valor del $10 \%$.

Por último, la prueba escrita será una aplicación de los conocimientos adquiridos a lo largo del curso, con el análisis de un proyecto de ApS de acuerdo con los contenidos presentados en clase. Tendrá un valor del 30\%.

Todos estos instrumentos nos han servido para establecer el éxito general del ciclo de mejora, pudiendo apreciarse no solo un cambio en las ideas de los estudiantes, sino también en su manera de entender la educación y el mundo que les rodea y su capacidad de mejorarlo. Este empoderamiento del alumnado como agente de cambio social es uno de los principios que han ido marcando nuestra docencia en los últimos dos años y que pretendemos mantener con la aplicación de metodologías activas que pongan al alumno en el centro del aprendizaje al tiempo que lo conectan con una realidad más allá de las aulas. En este sentido, uno de los elementos que habría que mantener sería la constante actualización de los temas presentados, facilitando esa conexión. Como mejoras de cara al curso que viene, se plantea el aumento del tiempo dedicado a la aplicación y diseño de los proyectos, comenzando desde el principio del cuatrimestre, aunque siempre manteniendo la dinámica de las sesiones, de carácter teórico-práctico. Igualmente, creemos necesario retomar la idea de enfrentar a los alumnos con sus propias palabras e ideas respecto a su futura labor docente, consiguiendo así que establezcan esa relación entre el espacio del aula universitaria, el mundo exterior y su propio desempeño profesional. Por último, proponemos seguir la línea de los CIMA previos en los que hemos realizado una revisión profunda de la metodología (curso 17/18 y los contenidos (cursos 18/19 y 19/20) planteando una necesaria revisión de la evaluación para el curso 20/21.

Jornadas de Formación e Innovación Docente del Profesorado | № 2 (2019)

Esta obra se distribuye con la licencia Creative Commons 


\section{Referencias bibliográficas}

Finkel, D. (2000). Dar clase con la boca cerrada. Valencia: Publicaciones de la Universidad de Valencia.

Porlán, R. (Coord.) Enseñanza universitaria. Cómo mejorarla. Madrid: Morata.

Rubio, L. y Escofet, A. (Coords.) (2017). Aprendizaje-servicio (ApS): claves para su desarrollo en la Universidad. Barcelona: Octaedro.

Jornadas de Formación e Innovación Docente del Profesorado | № 2 (2019) 